\title{
High-Resolution Absolute Position Vernier Shaft Encoder Suitable for High-Performance PMSM Servo Drives
}

\author{
Shashank Wekhande and Vivek Agarwal, Senior Member, IEEE
}

\begin{abstract}
Permanent magnet synchronous motor (PMSM) drives are suitable for high-performance servo applications, as in robotics. This, however, requires an accurate position feedback, which is not possible with the existing absolute position encoders, unless one is prepared to compromise on the size of the encoder. This paper proposes a new encoding scheme based on the simple Vernier principle. The proposed scheme improves the resolution of the encoder within limited disk diameter. An improved encoder based on the same principle is also presented with minor modifications to improve the resolution. Computer simulations and experimental work have shown that a suitable modification of the Vernier concept can result in an encoder that is superior to the existing ones. Details of this work are presented.
\end{abstract}

Index Terms-Absolute position, encoder, incremental, rotary, servo drive, Vernier.

\section{INTRODUCTION}

$\mathbf{P}$ ERMANENT magnet synchronous motor (PMSM) drives have become very popular these days owing to the wellknown advantages they offer over other types. Apart from other things, PMSM drives are suitable for high-performance servo applications [1]-[3]. They have become very popular for motion control applications (e.g., robotics), especially in the low to medium power range. PMSM offers high air gap flux density, high power density, high torque to inertia ratio, and high torque capability. It has a higher efficiency than the induction motor and is less sensitive to parameter variations. The superiority of PMSM drives, however, is contingent upon the fact that feedback devices must have a high resolution, meaning they are able to give feedback on the shaft position information with utmost accuracy.

Shaft angle encoders are a form of analog-to-digital converters in which the analog shaft angle is converted into the corresponding digital code in the form of electrical pulses or bits, which can be fed into the data processing equipment. Optical encoders are widely used in sophisticated drives, numerically controlled machines, digital servo systems, radar antennas, and robots as position feedback indicators [4].

Rotary encoders are mainly classified as [5] 1) incremental encoders or 2) absolute position encoders.

Incremental encoders provide a train of pulses with displacement of the shaft. The number of pulses read relative to

Manuscript received December 5, 2003; revised August 26, 2005.

The authors are with the Department of Electrical Engineering, Indian Institute of Technology, Bombay 400076, India (e-mail: agarwal@ee.iitb.ac.in).

Digital Object Identifier 10.1109/TIM.2005.862020 the reference position directly indicates the shaft displacement. The direction of shaft rotation is sensed by using two spatially displaced symmetrical tracks. An optional third track is used to sense the initial reference position. Such encoders can be used to count the number of full revolutions. Incremental encoders are simpler but provide relative displacement only. Also, they are prone to noise, and fatal error may occur on power fail restart. An incremental position encoder having three tracks is shown in Fig. 1(a), and the sensing scheme is shown in Fig. 1(b).

Absolute encoders employ multiple tracks and parallel output sensors to read the absolute position. Cyclic or unit distance code (Gray code) is normally used to minimize transition error or flashing. In the cyclic code, successive digit columns have absolute value $1,3,7,15,31,63, \ldots$, etc. [6]. In general, the $k$ th digit column (counting the rightmost column as column1) has an absolute value given by

$$
P=S \sum_{j=0}^{k-1} 2^{j} .
$$

The sign "S" of successive columns alternates with the most significant one having a positive value. An absolute position encoder having three tracks is shown in Fig. 2(a), and the sensing scheme is shown in Fig. 2(b).

However, these encoders suffer from the inherent problem of quantization noise on account of the limited resolution they possess. This noise is amplified when a backward operator is used to estimate the speed and acceleration from angular position information [7]. Several authors have proposed techniques to attenuate this noise [7]-[12]. Tilli and Montanari [7] have demonstrated high noise rejection by switching between two types of filtering (narrow and wide) based on the bandwidth of signals for speed and position estimation. For accurate estimation in a noisy environment, the Kalman filter, which is an optimal state estimator, is used [8], [9]. Another technique, in which the incremental shaft encoder uses three read heads, as against a single one in the case of conventional encoders, for resolving angular positions as well as small horizontal and vertical motion of the shafts accurately, has also been proposed [10]. In addition, advanced processors such as DSPs have been used in the feedback loop with adaptive algorithms to evaluate the speed and reduce noise [11], [12].

A major challenge is to achieve a high-precision performance from these encoders. A completely new technique, which 


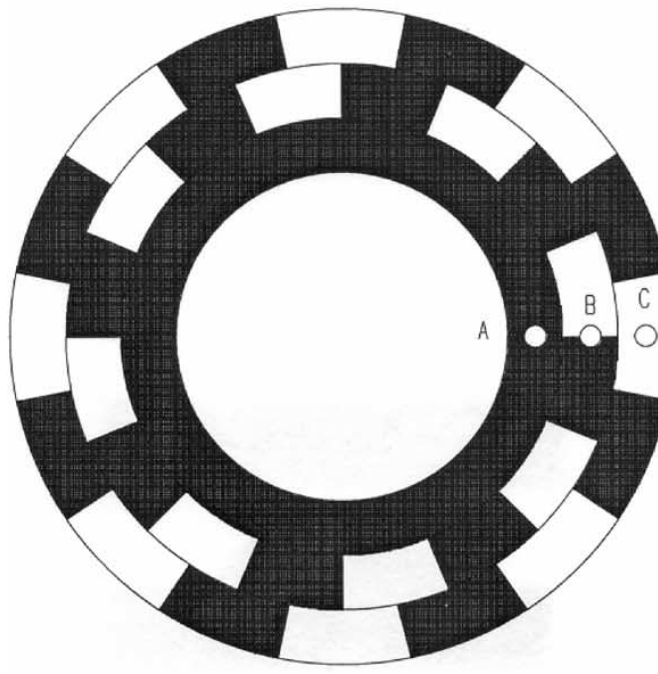

(a)

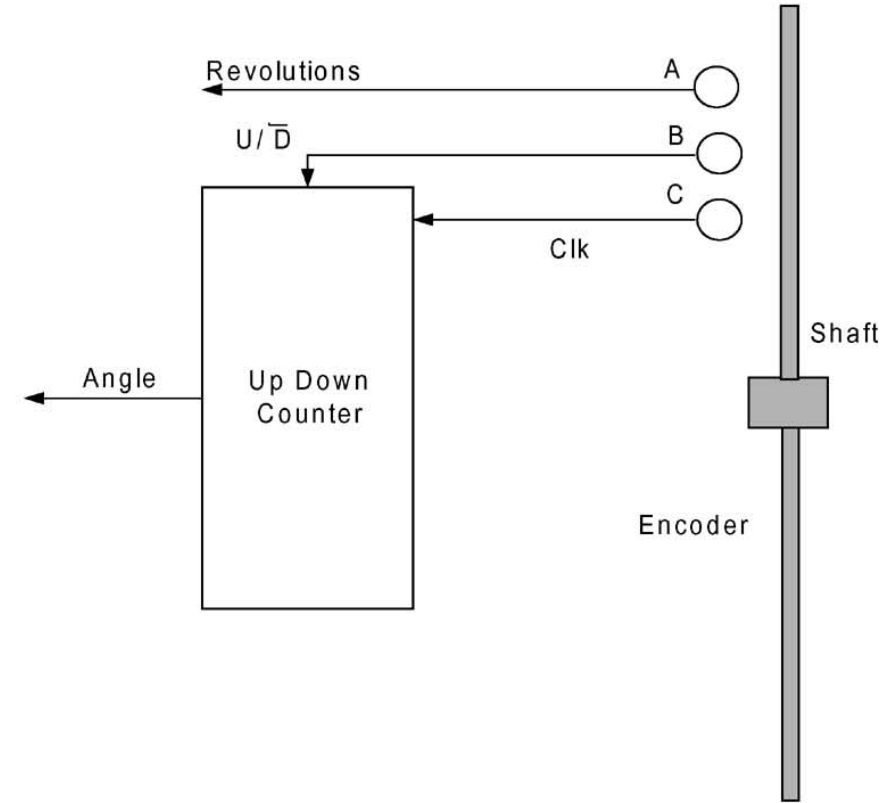

(b)

Fig. 1. (a) Incremental encoder. (b) Sensing scheme for incremental encoder.

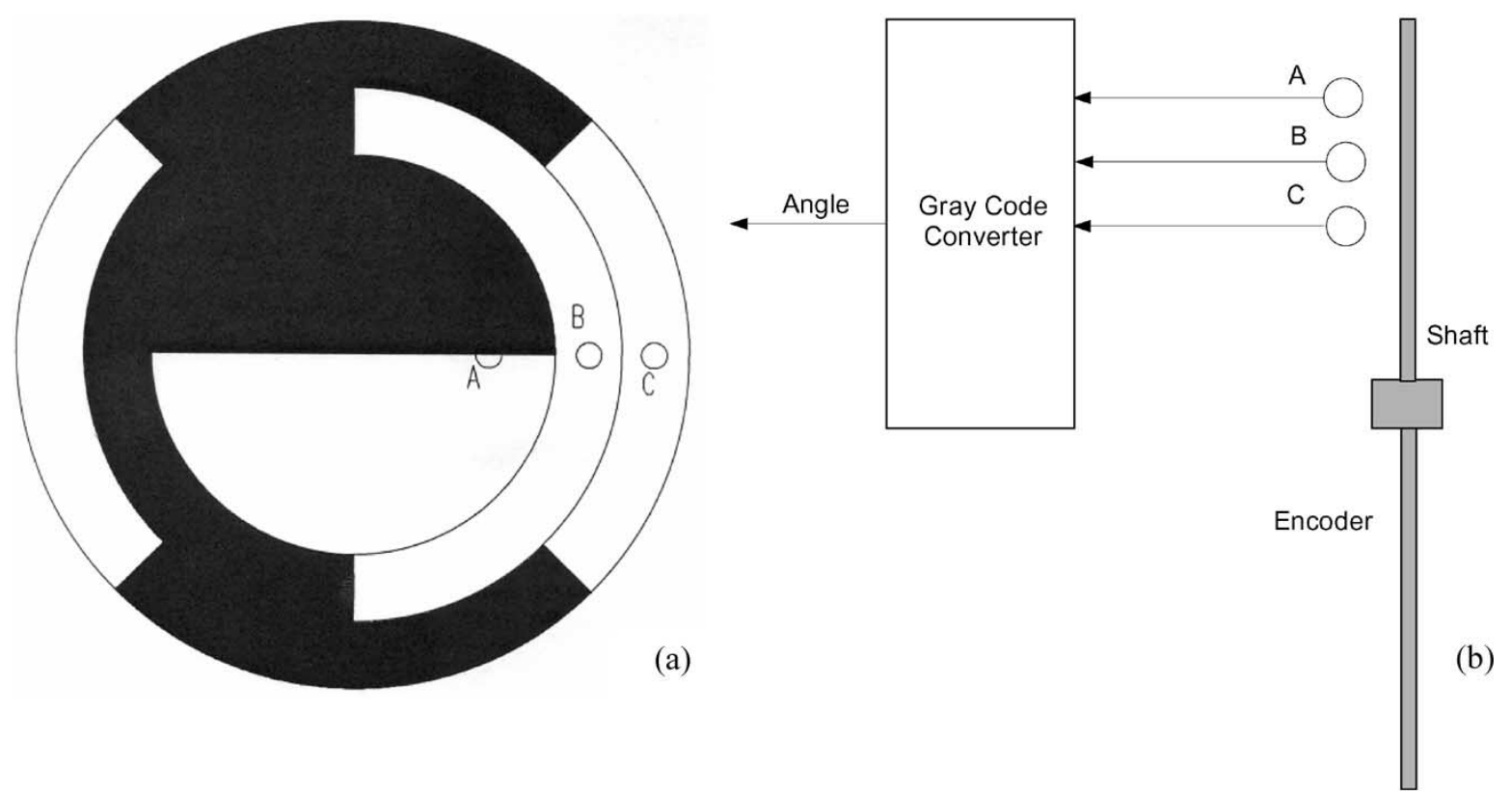

Fig. 2. (a) Absolute position encoder. (b) Sensing scheme for absolute position encoder.

greatly enhances the feedback resolution, is presented in this paper. The proposed technique is based on the well-known Vernier principle. It may be recalled that the Vernier method for measurement of length uses two scales: 1) a main scale with larger divisions and 2) a small movable auxiliary scale with smaller divisions to increase the resolution.

Fig. 3 shows a measurement using the Vernier principle. It should be noted that ten divisions of the Vernier scale have the same length as nine divisions of the main scale. For angular Vernier (as is relevant to encoder applications), the same principle applies. For a $0.1^{\circ}$ resolution, for example, one may have the main scale divided into $360 \times 1^{\circ}$ increments and the Vernier scale divided into ten graduations over $9^{\circ}$ of the main scale. In the proposed scheme, we are using $N(=3)$ main tracks with four segments in the third track and one auxiliary track with $2^{N} \pm 1$ (=7 or 9 ) segments. This resembles the Vernier principle described above, hence, the name.

This paper is organized into five sections. Section II describes the proposed absolute position Vernier encoder. Construction of the encoder and resolution calculations are explained in this section. A generalized example with a three-track main scale has been considered. An improved version of the proposed absolute position Vernier encoder is presented in Section III. The designed encoder was used in an experimental servo drive 


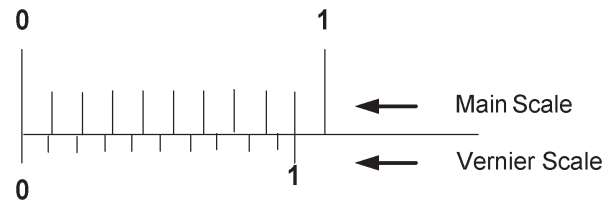

Fig. 3. Vernier principle.

as a position feedback sensor. Those details are presented in Section IV.

\section{Absolute Position Vernier Encoders}

Conventional absolute shaft position encoders require large numbers of sensors and tracks for higher resolution. Resolution of such an encoder having " $\mathrm{N}$ " tracks is given by

$$
\text { resolution }=\frac{360^{\circ}}{2^{N}} .
$$

The resolution of these encoders is upper bounded by geometry of sensors and accuracy in precision work. Simple techniques are proposed to improve resolution using the Vernier principle. A higher resolution is obtained with low-cost sensors, smaller diameter disks, and lower precision workmanship. The proposed encoder gives better mechanical stability for the disk connected to shaft as the disk is supported by "C"-type opto-couplers.

The Vernier absolute position encoder disk has inner cyclic code tracks similar to conventional encoders, used as "main" scale. The "N" track main disk is used along with $N$ sensors to read with basic resolution of $360^{\circ} /\left(2^{N}\right)$. The "auxiliary" scale is the outermost track having $2^{N}$ thin slits, displaced uniformly over the complete periphery. The slits are displaced by an angle of $360^{\circ} / 2^{N}$.

The number of sensors for auxiliary scale may be $2^{N}-1$ (low resolution) or $2^{N}+1$ (high resolution). These sensors are placed symmetrically over the outer track. Thus, there are $2^{\mathrm{N}}$ thin slits on the disk and $2^{N}-1$ or $2^{N}+1$ sensors for auxiliary scale. The difference between a sensor and the nearest slit is the resolution of the encoder. For example, an absolute position Vernier encoder with $N=3$ having seven sensors on auxiliary scale is shown in Fig. 4. The inner three tracks represent the main scale with three sensors A, B, and C. The outermost track is the proposed auxiliary track with sensors S1-S7.

In Fig. 4, sensor S1 coincides with the slit. If the disk is rotated in an anti-clockwise direction, sensor S2 will coincide with the disk, and in a clockwise direction, sensor S7 will coincide. The displacement between two consecutive sensors is $360^{\circ} /\left(2^{N}-1\right)$ while the displacement between two consecutive slits is $360^{\circ} / 2^{N}$.

Therefore, the resolution of the disk is the difference of the two and can be shown to be

$$
\text { resolution }=\frac{360^{\circ}}{2^{N}\left(2^{N}-1\right)} .
$$

As the disk rotates, successive sensors on the auxiliary scale coincide with any one of the slits. All the sensors on the Vernier disk coincide once within $360^{\circ} / 2^{N}$. Within this displacement,

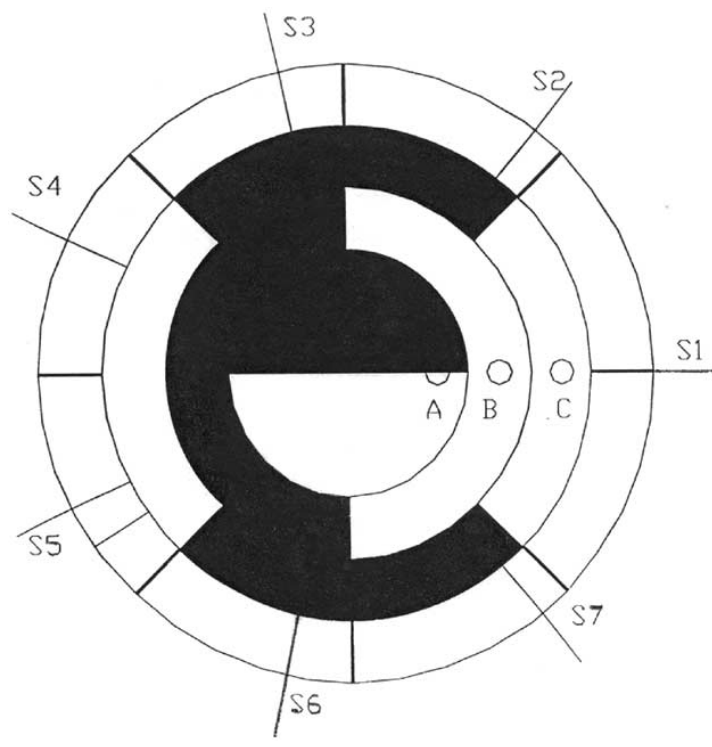

Fig. 4. Absolute position Vernier encoder for seven sensors on the auxiliary scale.

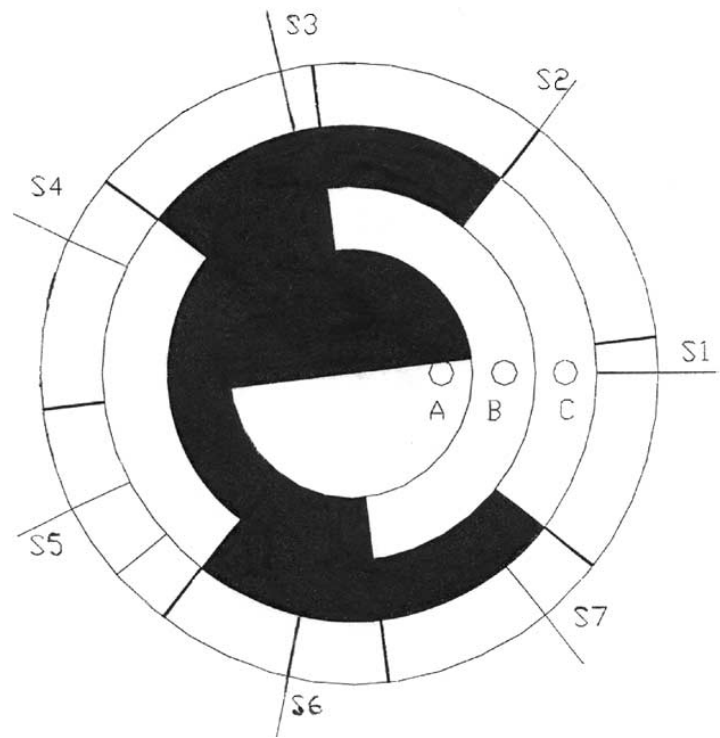

Fig. 5. Absolute position Vernier encoder for seven sensors on the auxiliary scale at $6.4^{\circ}$

the status on the main scale remains unaltered. The main scale reading advances and the auxiliary scale resets at this displacement. Fig. 4 shows the encoder at $0^{\circ}$ position. Figs. 5 and 6 show the encoder at $6.4^{\circ}$ and $45^{\circ}$ displacement. As seen from Fig. 5, sensor S2 coincides with the slit after $6.4^{\circ}$ of displacement. The status of the main scale remains same. Similarly, successive sensors will coincide with auxiliary disk slits as the disk rotates through $45^{\circ}$. As shown in Fig. 6, after $45^{\circ}$ of displacement, the main scale reading changes and the auxiliary scale resets with sensor S1 coinciding with the slit. As in a conventional Vernier scale, the actual displacement is the sum of auxiliary scale and main scale readings.

Transition error occurs when there are two simultaneous changes on the main disk or auxiliary scale. To avoid transition error, the thin slits on the auxiliary scale are displaced by 


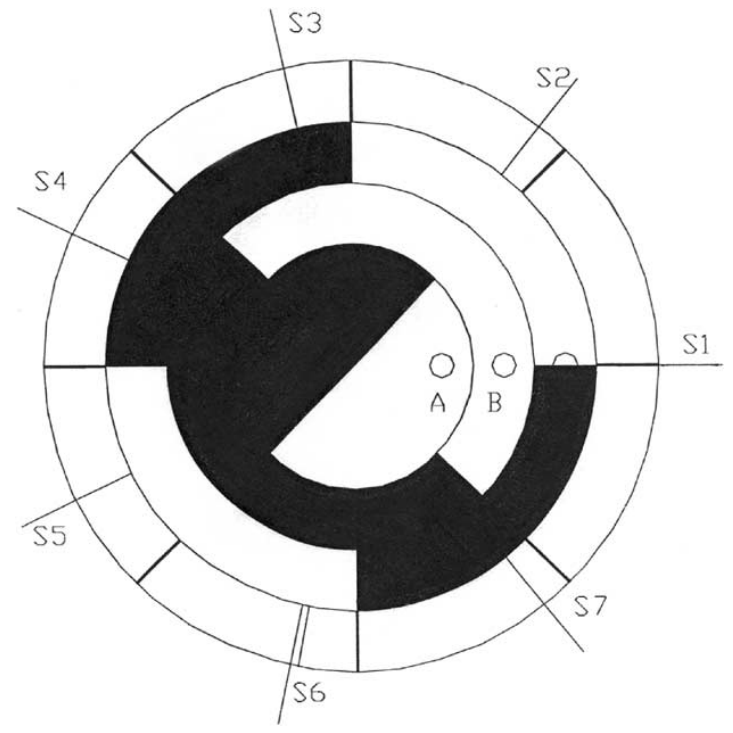

Fig. 6. Absolute position Vernier encoder for seven sensors on the auxiliary scale at $45^{\circ}$.

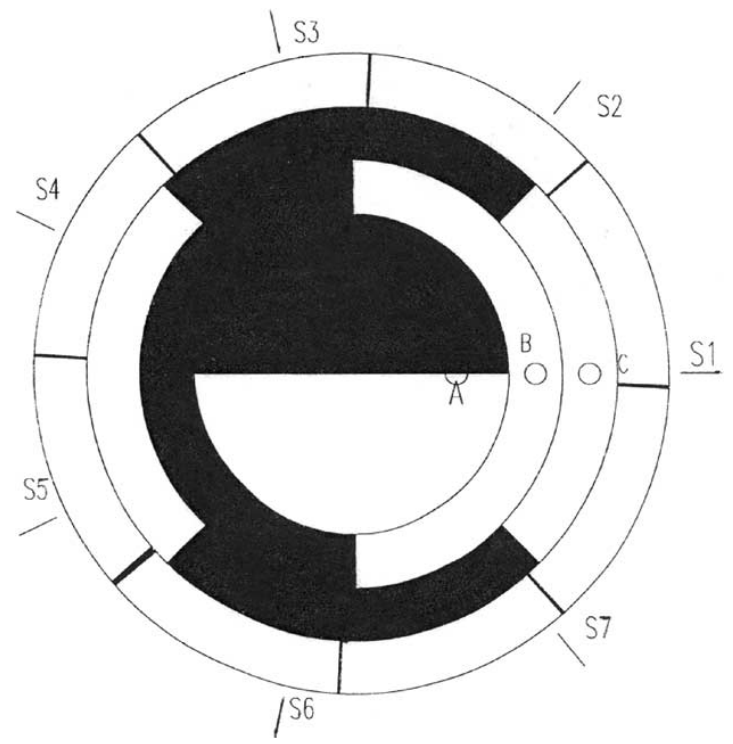

Fig. 7. Absolute position Vernier encoder for seven sensors on the auxiliary scale with displacement of slits to avoid transition error.

an offset angle equal to resolution/2 with respect to the main scale. This encoder is shown in Fig. 7. The resolution now gets modified to

$$
\text { resolution }= \pm \frac{360^{\circ}}{2^{N+1}\left(2^{N}-1\right)}
$$

For $N=3$, conventional encoders provide a resolution of $45^{\circ}$ or $\pm 22.5^{\circ}$, whereas the proposed encoder with $N=3$ and seven sensors on auxiliary disk provides a resolution of $\pm 3.2^{\circ}$.

Similarly, the resolution for an encoder having $2^{N}+1$ auxiliary sensors is given by

$$
\text { resolution }=\frac{360^{\circ}}{2^{N}\left(2^{N}+1\right)}
$$

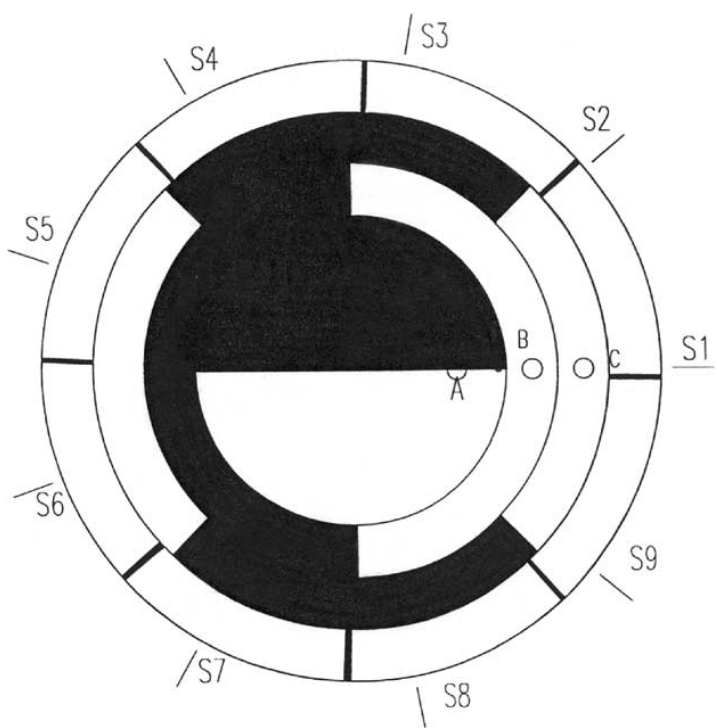

Fig. 8. Absolute position Vernier encoder for nine sensors on the auxiliary scale.

TABLE I

Status of Auxiliary Scale With Seven Sensors

\begin{tabular}{|l|l|l|l|l|l|l|l|}
\hline $\begin{array}{l}\text { Sensor } \Rightarrow \\
\text { Angle } \\
\text { (degrees) } \\
\text { anticlockwise }\end{array}$ & S1 & S2 & S3 & S4 & S5 & S6 & S7 \\
\hline 0 & 0 & 0 & 0 & 0 & 0 & 0 & 0 \\
\hline 3.21 & 1 & 0 & 0 & 0 & 0 & 0 & 0 \\
\hline 9.64 & 0 & 1 & 0 & 0 & 0 & 0 & 0 \\
\hline 16.07 & 0 & 0 & 1 & 0 & 0 & 0 & 0 \\
\hline 22.5 & 0 & 0 & 0 & 1 & 0 & 0 & 0 \\
\hline 28.93 & 0 & 0 & 0 & 0 & 1 & 0 & 0 \\
\hline 35.16 & 0 & 0 & 0 & 0 & 0 & 1 & 0 \\
\hline 41.79 & 0 & 0 & 0 & 0 & 0 & 0 & 1 \\
\hline 45 & 0 & 0 & 0 & 0 & 0 & 0 & 0 \\
\hline
\end{tabular}

and with an offset angle equal to half resolution, the actual resolution is

$$
\text { resolution }= \pm \frac{360^{\circ}}{2^{N+1}\left(2^{N}+1\right)} \text {. }
$$

With $N=3$ and nine sensors on the auxiliary scale, the resolution obtained is $\pm 2.5^{\circ}$. A Vernier encoder with $N=3$ and nine sensors on the auxiliary scale is shown in Fig. 8.

The statuses of the outer sensors of the proposed encoder with $N=3$ over $45^{\circ}$ displacement for low-resolution (seven sensors) and high-resolution (nine sensors) schemes are shown in Tables I and II, respectively. This table repeats identically after every $45^{\circ}$ displacement with change in the main scale reading.

Sensors S1 to S9 are "1" when the sensor and opaque slit coincide and " 0 " when the sensor and transparent part of the disk coincide.

This encoder is not a true absolute position sensor as the sensor and slit coincide at some fixed positions only. In between these displacements, all sensors on the auxiliary scale are "0." This may lead to a maximum starting error of $45^{\circ}$, but will be corrected within a displacement equal to the least count of 
TABLE II

Status of Auxiliary SCALE With Nine SENSORS

\begin{tabular}{|l|l|l|l|l|l|l|l|l|l|}
\hline $\begin{array}{l}\text { Sensor } \Rightarrow \\
\text { Angle } \\
\text { (degrees) } \\
\text { anticlockwise }\end{array}$ & S1 & S2 & S3 & S4 & S5 & S6 & S7 & S8 & S9 \\
\hline 0 & 0 & 0 & 0 & 0 & 0 & 0 & 0 & 0 & 0 \\
\hline 2.5 & 1 & 0 & 0 & 0 & 0 & 0 & 0 & 0 & 0 \\
\hline 7.5 & 0 & 0 & 0 & 0 & 0 & 0 & 0 & 0 & 1 \\
\hline 12.5 & 0 & 0 & 0 & 0 & 0 & 0 & 0 & 1 & 0 \\
\hline 17.5 & 0 & 0 & 0 & 0 & 0 & 0 & 1 & 0 & 0 \\
\hline 22.5 & 0 & 0 & 0 & 0 & 0 & 1 & 0 & 0 & 0 \\
\hline 27.5 & 0 & 0 & 0 & 0 & 1 & 0 & 0 & 0 & 0 \\
\hline 32.5 & 0 & 0 & 0 & 1 & 0 & 0 & 0 & 0 & 0 \\
\hline 37.5 & 0 & 0 & 1 & 0 & 0 & 0 & 0 & 0 & 0 \\
\hline 42.5 & 0 & 1 & 0 & 0 & 0 & 0 & 0 & 0 & 0 \\
\hline 45 & 0 & 0 & 0 & 0 & 0 & 0 & 0 & 0 & 0 \\
\hline & & & & & & & \\
\hline
\end{tabular}

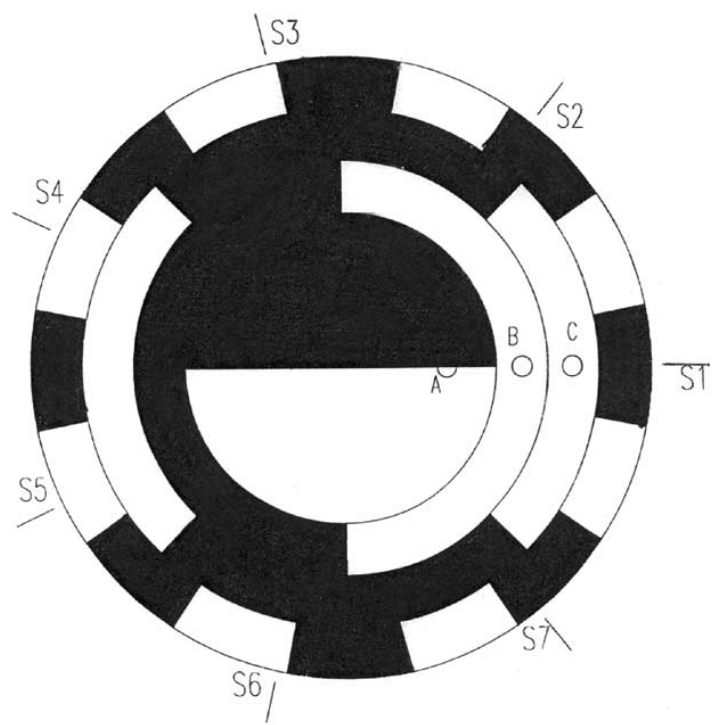

Fig. 9. Improved absolute position Vernier encoder with seven sensors on the auxiliary scale.

auxiliary scale. Also during normal operation, the microcontroller has to sample and hold the last reading for auxiliary scale for least count displacement to avoid error.

\section{Improved AbSOLUte Position VERNIER ENCODERS}

The resolution of the Vernier encoder can still be improved by replacing thin slits on the auxiliary disk with alternate opaque and transparent patches. This also provides a true absolute position encoder eliminating the need of a sample and hold. The Vernier encoder has only one change in sensor status at a time over complete revolution.

The improved Vernier scale has a main scale and an auxiliary scale. The main scale having $N$ tracks provides a basic resolution of $360^{\circ} / 2^{N}$. The auxiliary scale has $2^{N}$ alternate transparent and opaque patches distributed uniformly over the entire periphery. There can be $2^{N}+1$ or $2^{N}-1$ sensors on the auxiliary scale. As the disk rotates, multiple sensors sense the displacement. An improved absolute position Vernier encoder having seven and nine auxiliary sensors (with $N=3$ )

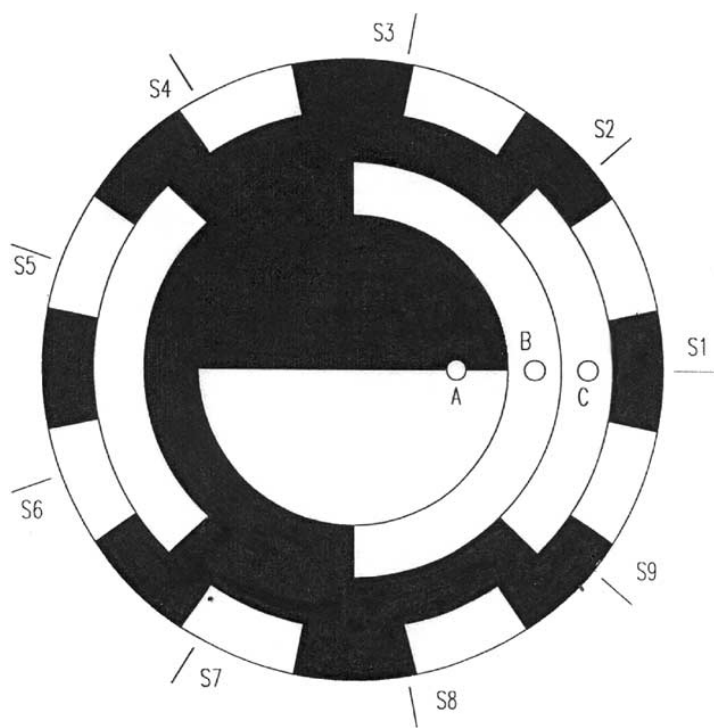

Fig. 10. Improved absolute position Vernier encoder with nine sensors on the auxiliary scale.

TABLE III

Status of Auxiliary SCAle With Seven SEnsors FOR IMPROVED VERNIER ENCODER

\begin{tabular}{|l|l|l|l|l|l|l|l|}
\hline $\begin{array}{l}\text { Sensor } \Rightarrow \\
\text { Angle } \\
\begin{array}{l}\text { degrees) } \\
\text { anticlockwise }\end{array}\end{array}$ & S1 & S2 & S3 & S4 & S5 & S6 & S7 \\
\hline 0 & 1 & 1 & 0 & 0 & 0 & 0 & 1 \\
\hline 1.607 & 1 & 1 & $\mathrm{X}$ & 0 & 0 & 0 & 1 \\
\hline 3.214 & 1 & 1 & 1 & 0 & 0 & 0 & 1 \\
\hline 4.821 & 1 & 1 & 1 & 0 & 0 & 0 & $\mathrm{X}$ \\
\hline 6.428 & 1 & 1 & 1 & 0 & 0 & 0 & 0 \\
\hline 8.035 & 1 & 1 & 1 & $\mathrm{X}$ & 0 & 0 & 0 \\
\hline 9.642 & 1 & 1 & 1 & 1 & 0 & 0 & 0 \\
\hline 11.25 & $\mathrm{X}$ & 1 & 1 & 1 & 0 & 0 & 0 \\
\hline 12.857 & 0 & 1 & 1 & 1 & 0 & 0 & 0 \\
\hline 14.464 & 0 & 1 & 1 & 1 & $\mathrm{X}$ & 0 & 0 \\
\hline 16.071 & 0 & 1 & 1 & 1 & 1 & 0 & 0 \\
\hline 17.678 & 0 & $\mathrm{X}$ & 1 & 1 & 1 & 0 & 0 \\
\hline 19.285 & 0 & 0 & 1 & 1 & 1 & 0 & 0 \\
\hline 20.893 & 0 & 0 & 1 & 1 & 1 & $\mathrm{X}$ & 0 \\
\hline 22.5 & 0 & 0 & 1 & 1 & 1 & 1 & 0 \\
\hline 24.107 & 0 & 0 & $\mathrm{X}$ & 1 & 1 & 1 & 0 \\
\hline 25.714 & 0 & 0 & 0 & 1 & 1 & 1 & 0 \\
\hline 27.321 & 0 & 0 & 0 & 1 & 1 & 1 & $\mathrm{X}$ \\
\hline 28.928 & 0 & 0 & 0 & 1 & 1 & 1 & 1 \\
\hline 30.535 & 0 & 0 & 0 & $\mathrm{X}$ & 1 & 1 & 1 \\
\hline 32.143 & 0 & 0 & 0 & 0 & 1 & 1 & 1 \\
\hline 33.75 & $\mathrm{X}$ & 0 & 0 & 0 & 1 & 1 & 1 \\
\hline 35.357 & 1 & 0 & 0 & 0 & 1 & 1 & 1 \\
\hline 36.964 & 1 & 0 & 0 & 0 & $\mathrm{X}$ & 1 & 1 \\
\hline 38.571 & 1 & 0 & 0 & 0 & 0 & 1 & 1 \\
\hline 40.178 & 1 & $\mathrm{X}$ & 0 & 0 & 0 & 1 & 1 \\
\hline 41.785 & 1 & 1 & 0 & 0 & 0 & 1 & 1 \\
\hline 43.392 & 1 & 1 & 0 & 0 & 0 & $\mathrm{X}$ & 1 \\
\hline 45 & 1 & 1 & 0 & 0 & 0 & 0 & 1 \\
\hline & & & & & & \\
\hline
\end{tabular}

is shown in Figs. 9 and 10, respectively. The auxiliary sensor output is " 1 " when the sensor and opaque portion of the auxiliary disk coincide and is " 0 " when the sensor and transparent portion match. The actual displacement is the sum of the main scale reading and the auxiliary scale reading. 
TABLE IV

STATUS OF AUXILIARY SCALE FOR IMPROVED VERNIER ENCODER WITH NINE SENSORS

\begin{tabular}{|l|l|l|l|l|l|l|l|l|l|}
\hline $\begin{array}{l}\text { Sensor } \Rightarrow \\
\text { Angle } \\
\begin{array}{l}\text { degrees) } \\
\text { anticlockwise }\end{array}\end{array}$ & S1 & S2 & S3 & S4 & S5 & S6 & S7 & S8 & S9 \\
\hline 0 & 1 & 1 & 1 & 0 & 0 & 0 & 0 & 1 & 1 \\
\hline 1.25 & 1 & 1 & $\mathrm{X}$ & 0 & 0 & 0 & 0 & 1 & 1 \\
\hline 2.5 & 1 & 1 & 0 & 0 & 0 & 0 & 0 & 1 & 1 \\
\hline 3.75 & 1 & 1 & 0 & 0 & 0 & 0 & $\mathrm{X}$ & 1 & 1 \\
\hline 4 & 1 & 1 & 0 & 0 & 0 & 0 & 1 & 1 & 1 \\
\hline 6.25 & 1 & $\mathrm{X}$ & 0 & 0 & 0 & 0 & 1 & 1 & 1 \\
\hline 7.5 & 1 & 0 & 0 & 0 & 0 & 0 & 1 & 1 & 1 \\
\hline 8.75 & 1 & 0 & 0 & 0 & 0 & $\mathrm{X}$ & 1 & 1 & 1 \\
\hline 10 & 1 & 0 & 0 & 0 & 0 & 1 & 1 & 1 & 1 \\
\hline 11.25 & $\mathrm{X}$ & 0 & 0 & 0 & 0 & 1 & 1 & 1 & 1 \\
\hline 12.5 & 0 & 0 & 0 & 0 & 0 & 1 & 1 & 1 & 1 \\
\hline 13.75 & 0 & 0 & 0 & 0 & $\mathrm{X}$ & 1 & 1 & 1 & 1 \\
\hline 15 & 0 & 0 & 0 & 0 & 1 & 1 & 1 & 1 & 1 \\
\hline 16.25 & 0 & 0 & 0 & 0 & 1 & 1 & 1 & 1 & $\mathrm{X}$ \\
\hline 17.5 & 0 & 0 & 0 & 0 & 1 & 1 & 1 & 1 & 0 \\
\hline 18.75 & 0 & 0 & 0 & $\mathrm{X}$ & 1 & 1 & 1 & 1 & 0 \\
\hline 20 & 0 & 0 & 0 & 1 & 1 & 1 & 1 & 1 & 0 \\
\hline 21.25 & 0 & 0 & 0 & 1 & 1 & 1 & 1 & $\mathrm{X}$ & 0 \\
\hline 22.5 & 0 & 0 & 0 & 1 & 1 & 1 & 1 & 0 & 0 \\
\hline 23.75 & 0 & 0 & $\mathrm{X}$ & 1 & 1 & 1 & 1 & 0 & 0 \\
\hline 25 & 0 & 0 & 1 & 1 & 1 & 1 & 1 & 0 & 0 \\
\hline 26.25 & 0 & 0 & 1 & 1 & 1 & 1 & $\mathrm{X}$ & 0 & 0 \\
\hline 27.5 & 0 & 0 & 1 & 1 & 1 & 1 & 0 & 0 & 0 \\
\hline 28.75 & 0 & $\mathrm{X}$ & 1 & 1 & 1 & 1 & 0 & 0 & 0 \\
\hline 30 & 0 & 1 & 1 & 1 & 1 & 1 & 0 & 0 & 0 \\
\hline 31.25 & 0 & 1 & 1 & 1 & 1 & $\mathrm{X}$ & 0 & 0 & 0 \\
\hline 32.5 & 0 & 1 & 1 & 1 & 1 & 0 & 0 & 0 & 0 \\
\hline 33.75 & $\mathrm{X}$ & 1 & 1 & 1 & 1 & 0 & 0 & 0 & 0 \\
\hline 35 & 1 & 1 & 1 & 1 & 1 & 0 & 0 & 0 & 0 \\
\hline 36.25 & 1 & 1 & 1 & 1 & $\mathrm{X}$ & 0 & 0 & 0 & 0 \\
\hline 37.5 & 1 & 1 & 1 & 1 & 0 & 0 & 0 & 0 & 0 \\
\hline 38.75 & 1 & 1 & 1 & 1 & 0 & 0 & 0 & 0 & $\mathrm{X}$ \\
\hline 40 & 1 & 1 & 1 & 1 & 0 & 0 & 0 & 0 & 1 \\
\hline 41.25 & 1 & 1 & 1 & $\mathrm{X}$ & 0 & 0 & 0 & 0 & 1 \\
\hline 42.5 & 1 & 1 & 1 & 0 & 0 & 0 & 0 & 0 & 1 \\
\hline 43.75 & 1 & 1 & 1 & 0 & 0 & 0 & 0 & $\mathrm{X}$ & 1 \\
\hline 45 & 1 & 1 & 1 & 0 & 0 & 0 & 0 & 1 & 1 \\
\hline & & & & & & & \\
\hline
\end{tabular}

The resolution of this encoder for $2^{N}-1$ auxiliary sensors is given by

$$
\text { resolution }=\frac{360^{\circ}}{2^{N+1}\left(2^{N}-1\right)}
$$

and for $2^{N}+1$ auxiliary sensors resolution is given by

$$
\text { resolution }=\frac{360^{\circ}}{2^{N+1}\left(2^{N}+1\right)} .
$$

The auxiliary disk can be displaced with respect to the sensors by an offset equal to half the resolution to reduce the absolute error in reading.

The resolution of this encoder, for $2^{N}-1$ auxiliary sensors, is given by

$$
\text { resolution }= \pm \frac{360^{\circ}}{2^{N+2}\left(2^{N}-1\right)}
$$

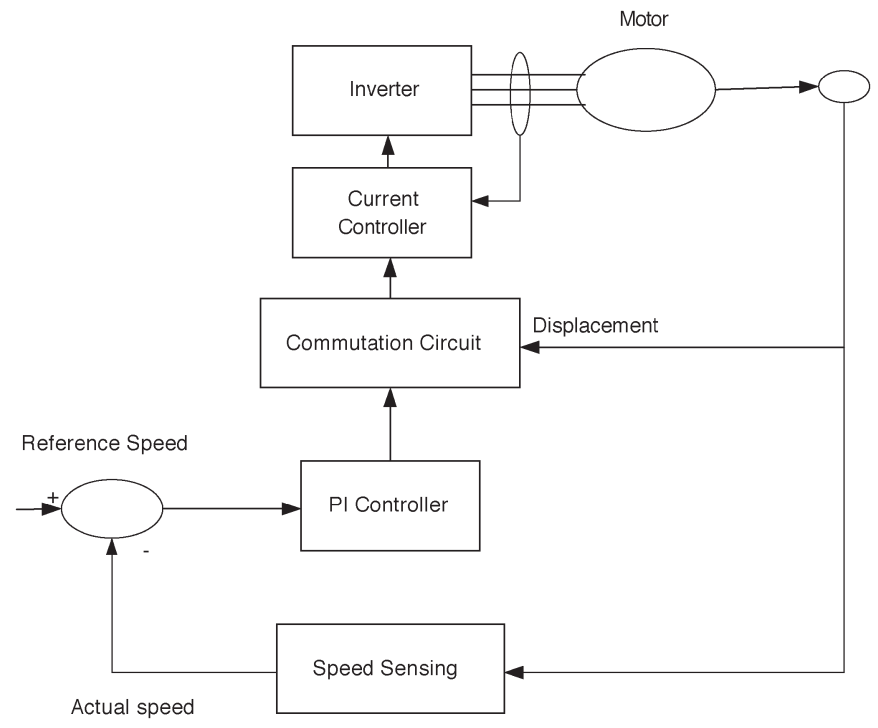

Fig. 11. Typical servo drive.

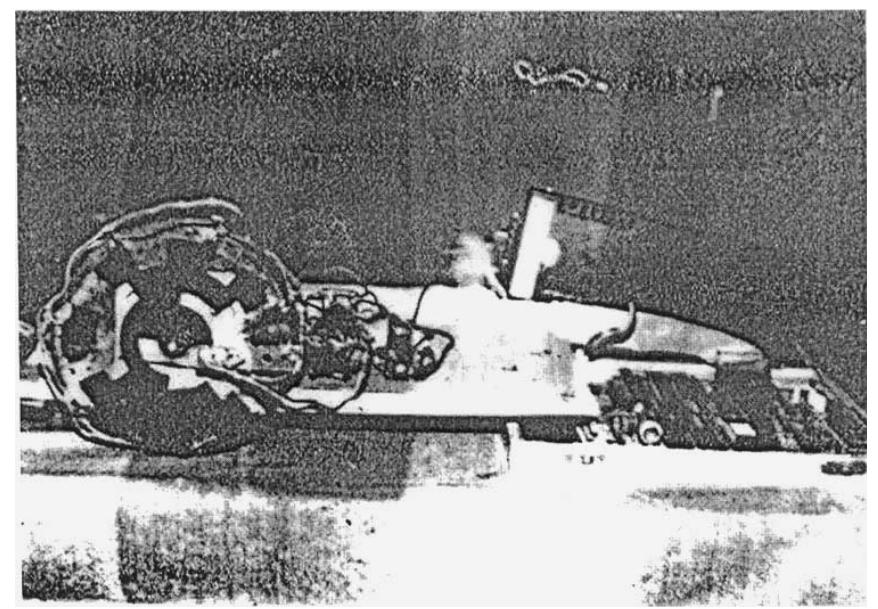

Fig. 12. Photograph of the experimental setup.

and for $2^{N}+1$ auxiliary sensors resolution is given by

$$
\text { resolution }= \pm \frac{360^{\circ}}{2^{N+2}\left(2^{N}+1\right)} \text {. }
$$

For $N=3$ and seven sensors on the auxiliary disk, the resolution is $\pm 1.6^{\circ}$ and for the nine-sensor scheme the resolution is $\pm 1.25^{\circ}$. To obtain a resolution of $1.25^{\circ}$ with a conventional $N$-track absolute position encoder, one would require nine tracks resulting in a much larger disk size, shown as follows.

- resolution available with a conventional absolute encoder $=360^{\circ} / 2^{N}$;

- resolution of $1.25^{\circ} \Rightarrow 2 N=360^{\circ} / 1.25$;

- $N=8.2 \approx 9$.

It may be seen in the Appendix that commercial companies offer a resolution of $10-13$ bits (corresponding to $0.35-0.04^{\circ}$ angular resolution). This level of resolution from a conventional encoder would require $10-13$ tracks. A 13 -bit $\left(0.04^{\circ}\right)$ resolution will be achieved with only six tracks (plus one auxiliary track) 

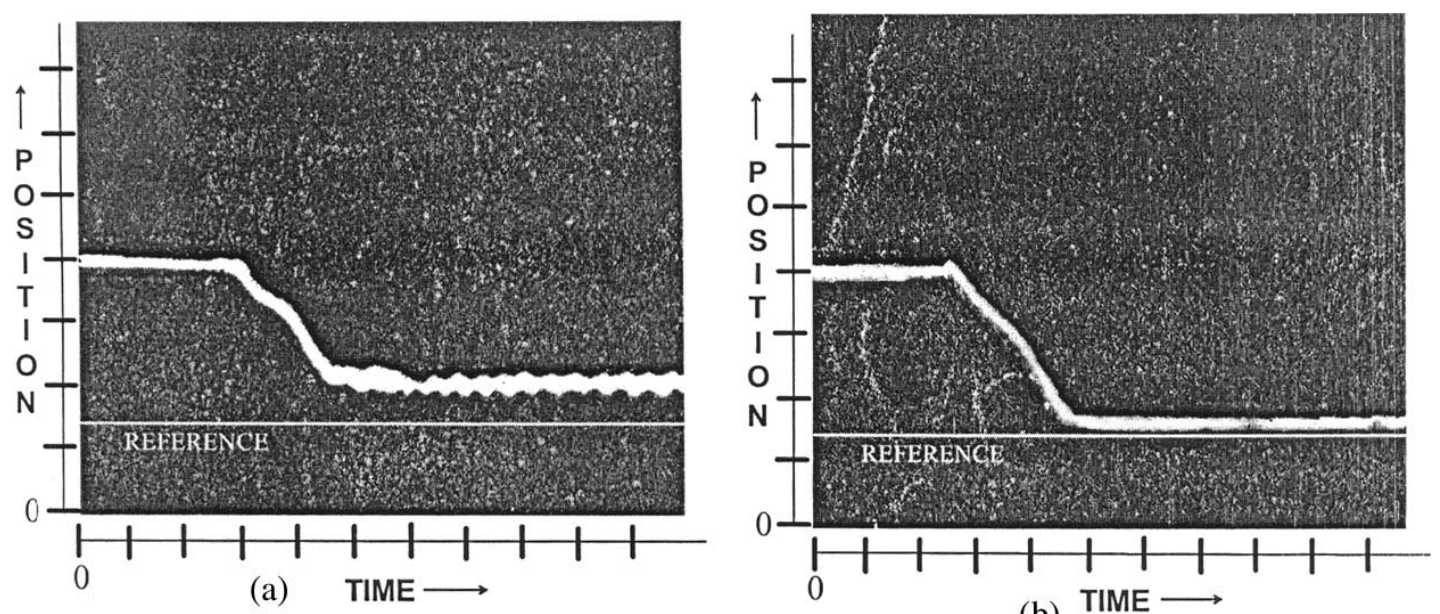

(b)

Fig. 13. Photograph for transient response of servo drive (a) with gray disk encoder and (b) with proposed encoder.

in case of the proposed absolute Vernier encoder scheme as shown below with the help of (6), i.e.,

$$
\begin{aligned}
\text { Resolution } & = \pm \frac{360^{\circ}}{2^{N+1}\left(2^{N}+1\right)} \\
& = \pm \frac{360^{\circ}}{2^{6+1}\left(2^{6}+1\right)} \\
& =0.04^{\circ} \Rightarrow N \approx 6 .
\end{aligned}
$$

The improved absolute Vernier encoder with the same number of tracks (six main tracks +1 auxiliary track) will be able to provide a still higher resolution as shown using (10), i.e.,

$$
\text { Resolution }= \pm \frac{360^{\circ}}{2^{N+2}\left(2^{N}+1\right)}= \pm \frac{360^{\circ}}{2^{6+2}\left(2^{6}+1\right)}=0.021^{\circ}
$$

It is clear that in comparison with conventional encoders, the disk size of Vernier encoders will be much smaller (typically a diameter of 3-4 in) for a given resolution. This size can be further reduced if better and precise manufacturing techniques are used. The above calculations clearly show the advantage of the proposed scheme when compared with the commercially available encoders (see the Appendix) in terms of size, resolution, and cost. The cost of building the laboratory prototype of the Vernier encoder was less than US \$20.

\section{EXPERIMENTAL VERIFICATION}

The proposed encoder is animated on the computer for simulation over $0-45^{\circ}$ displacement with $N=3$. The results of simulation of the outer sensors for a Vernier encoder with seven and nine sensors on the auxiliary scale are shown in Tables I and II. The results for an improved Vernier encoder with seven and nine sensors are shown in Tables III and IV. Here, "X" means that the sensor is at the edge of the patch.

A closed-loop servo drive is fabricated for rotating the shaft through a desired angular displacement. The block schematic for the drive is shown in Fig. 11. The proposed improved Vernier encoder with $N=3$ with nine sensors on the auxiliary scale was used as a position sensor. The encoder was fabricated by thick transparent polyester film. The required pattern was printed on a seat of polyester film. The encoder was cut in a circular fashion and fixtures were placed to couple the encoder to the shaft. Infrared circular LED-transistor pairs were used as the main scale sensors, and MOC 7811 infrared opto-couplers were used as auxiliary sensors. These sensors were fixed on a circular base-plate mounted on the motor frame, and the disk was coupled to the shaft directly. The photograph of the experimental setup is shown in Fig. 12.

Intel's 8051 is used as the microcontroller. Two ports are used for sensing the main and the auxiliary scale sensor status. The controller reads the main scale and auxiliary scale readings and converts the codes into an equivalent hexadecimal code using lookup tables. The lookup tables are derived from Table IV. The code read is then compared with the reference angle and the servo motor is driven through the proportional controller.

The performance of the drive is compared with the conventional gray disk encoder with $N=3$. The drive with the proposed encoder gives better accuracy and prevents continuous oscillation of the motor shaft due to large error steps. The transient response of the drive with the gray disk encoder and the proposed encoder is shown in Fig. 13.

\section{Conclusion}

The PMSM motor is suitable for servo drives for a variety of applications. A high-performance PMSM drive requires accurate position sensing. The proposed encoder is capable of providing the desired accuracy, thereby enhancing the drive's performance. Two schemes have been proposed in this paper. The first one is based on the absolute position Vernier principle and is capable of giving accuracy up to $3.2^{\circ}$ with seven sensors. The second one is a modified version of the first, capable of giving up to $1.6^{\circ}$ with seven sensors. This is in contrast with the existing ones that gave an accuracy of only $45^{\circ}$. The commonly used position Gray code encoders have limited accuracy due to limitations of size and workmanship.

Experiments show that an increase in accuracy improves the transient response too, making the proposed Vernier encoder 
TABLE V

\begin{tabular}{|c|c|c|c|c|c|c|}
\hline $\begin{array}{l}\text { Sr. } \\
\text { No }\end{array}$ & Name of the company & $\begin{array}{l}\text { Model name/ } \\
\text { No. }\end{array}$ & Size & Resolution & Output type & Cost \\
\hline 1 & $\begin{array}{l}\text { Dynamic Research Corp. } \\
\text { Willington, MA, USA } \\
\text { www.drc.com/encoder }\end{array}$ & $\begin{array}{l}\text { A } 25-\text { Heavy } \\
\text { Duty Absolute } \\
\text { Encoder }\end{array}$ & $\begin{array}{l}2.5 \text { inch } \\
\text { diameter }\end{array}$ & Upto 11 bit & $\begin{array}{l}\text { Gray code or } \\
\text { Natural binary }\end{array}$ & $\begin{array}{l}\text { US \$ } \\
450-475\end{array}$ \\
\hline 2 & $\begin{array}{l}\text { Gurley Precision } \\
\text { Instruments, Troy, NY } \\
\text { USA } \\
\text { www.gurley.com }\end{array}$ & $\begin{array}{l}\text { A } 25 \mathrm{~S} \text {-absolute } \\
\text { position encoder }\end{array}$ & $\begin{array}{l}2.5 \text { inch } \\
\text { diameter, } \\
2.25 \text { inch } \\
\text { thickness }\end{array}$ & $\begin{array}{l}\text { Maximum } \\
2^{17}(131072)\end{array}$ & $\begin{array}{l}\text { Natural } \\
\text { binary }\end{array}$ & $\begin{array}{l}\text { US \$ } \\
1300-2000\end{array}$ \\
\hline 3 & $\begin{array}{l}\text { Sumtak Corporation of } \\
\text { Japan } \\
\text { www.sumtak.com }\end{array}$ & $\begin{array}{l}25 \mathrm{AE} \text { Absolute } \\
\text { Encoder/Single } \\
\text { Turn-13 Bit }\end{array}$ & $\begin{array}{l}2.5 \text { inch } \\
\text { diameter } \\
4.25 \text { inch } \\
\text { thickness }\end{array}$ & $\begin{array}{l}\text { Resolution } 8 \\
\text { bit }(256) \text { to } \\
13 \text { bit } \\
(8192)\end{array}$ & $\begin{array}{l}\text { Gray code output } \\
\text { standard }\end{array}$ & $*$ \\
\hline 4 & $\begin{array}{l}\text { Stegmann Inc. Dayton } \\
\text { OH } 45414 \text { USA } \\
\text { www.stegmann.com }\end{array}$ & $\begin{array}{l}\text { CA } 20 \text { Absolute } \\
\text { position encoder }\end{array}$ & $\begin{array}{l}2 \text { inch } \\
\text { diameter. } \\
2 \text { inch } \\
\text { thickness }\end{array}$ & $\begin{array}{l}2 \text { to } 32768 \\
\text { Pulses Per } \\
\text { Revolution } \\
\text { (1 to15 bits) }\end{array}$ & $\begin{array}{l}\text { Gray and Excess } \\
\text { Gray codes, } \\
\text { Binary and } \\
\text { BCD with } \\
\text { parallel outputs }\end{array}$ & US \$ 315 \\
\hline
\end{tabular}

* Not known but presumed to be competitive

suitable for sophisticated servo drive applications such as space, robotics, and medical equipment.

\section{APPENDIX}

Table V shows some of the world's leading encoder manufacturers and the details of their products.

\section{REFERENCES}

[1] P. Pillay and R. Krishnan, "Application characteristics of permanent magnet synchronous and brushless DC motor for servo drives," IEEE Trans. Ind. Appl., vol. 27, no. 5, pp. 986-996, Sep./Oct. 1991.

[2] J. R. Handerson and T. J. E. Miller, The Design of Brushless Permanent Magnet Motors. Oxford, U.K.: Clarendon, 1994.

[3] S. R. Macminn and T. M. Jahns, "Control techniques for improved high speed performance of interior PM synchronous motor drive," IEEE Trans. Ind. Appl., vol. 27, no. 5, pp. 997-1004, Sep./Oct. 1991.

[4] M. H. Qureshi, "The role of electro-optical encoders in digitization of 3-dimensional image on stereo plotter," in Proc. Opto-electronic Imaging Conf., 1993, pp. 369-379.

[5] E. Doebelin, Measurement Systems: Applications and Design. New York: McGraw-Hill, 1990.

[6] P. H. Sydenham, Handbook of Measurement Science, vol. 2. Chichester, U.K.: Wiley, 1983.

[7] A. Tilli and M. Montanari, "A low-noise estimator of angular speed and acceleration from shaft encoder measurements," in Proc. 9th Mediterranean Conf. Control and Automation (MED), Dubrovnik, Croatia, Jun. 27-29, 2001. [Online]. Available: http://med.ee.nd.edu/ MED9/Papers/Drives_control/med01-105.pdf

[8] P. R. Belanger, P. Dobrovolny, A. Helmy, and X. Zhang, "Estimation of angular velocity and acceleration from shaft-encoder measurements," in Proc. IEEE Int. Conf. Robotics and Automation, Nice, France, 1992, pp. 585-592.
[9] T.-J. Kweon and D.-S. Hyun, "High performance speed control of electric machine using low-precision shaft encoder," IEEE Trans. Power Electron., vol. 14, no. 5, pp. 838-849, Sep. 1999.

[10] J. F. Poliakoff, P. D. Thomas, P. A. Orton, and A. Sackfield, "The incremental motion encoder: A new approach to high speed monitoring of rotating shafts," Meas. Control, vol. 33, no. 2, pp. 49-51, Mar. 2000.

[11] K.-Y. Cheng, C.-T. Yao, and Y.-Y. Tzou, "Adaptive target positioning control for permanent magnet synchronous motors with low-resolution shaft encoder," in Proc. 5th Int. Conf. Power Electronics and Drive Systems, Singapore, 2003, vol. 1, pp. 716-721.

[12] J. Lygouras, L. Konstantinos, and P. Tsalides, "High-performance position detection and velocity adaptive measurement for closed-loop position control," IEEE Trans. Instrum. Meas., vol. 47, no. 4, pp. 978-985, Aug. 1998.

Shashank Wekhande received the M.S. degree in electrical engineering from Amravati University, Maharashtra, India, and the Ph.D. degree from the Department of Electrical Engineering, Indian Institute of Technology, Bombay, India, in 2001.

While working toward the Ph.D. degree, he worked on static var compensators for applications in active line current conditioning and induction generator control. Subsequently, he worked with Lucent Technologies and Tyco Electronics.

Vivek Agarwal (S'92-M'93-SM'01) received the M.S. degree in electrical engineering from the Indian Institute of Science, Bangalore, India, and the Ph.D. degree from the Department of Electrical and Computer Engineering, University of Victoria, Victoria, BC, Canada.

He was a Research Engineer at Statpower Technologies, Burnaby, BC, before joining the Department of Electrical Engineering, Indian Institute of Technology, Bombay, India, where he is currently a Professor. His main field of interest is power electronics.

Dr. Agarwal is a Fellow of IETE and a Life Member of ISTE. 